\title{
DỨcin
}

Technological University Dublin

ARROW@TU Dublin

Articles

School of Electrical and Electronic Engineering

2003-01-01

\section{Circular Annular Planar Monopoles with EM Coupling}

\author{
Z. N. Chen \\ Institute for Infocomm Research \\ Max Ammann \\ Technological University Dublin, max.ammann@tudublin.ie \\ M.Y. W. Chia \\ Institute for Infocomm Research
}

See next page for additional authors

Follow this and additional works at: https://arrow.tudublin.ie/engscheceart

Part of the Electrical and Computer Engineering Commons

\section{Recommended Citation}

Chen, Z. et al. (2003) Circular annular planar monopoles with EM coupling. IEE Proceedings Microwaves, Antennas and Propagation,8 August, 2003, Vol.150, pp. 269-273. doi:10.1049/ip-map:20030476

This Article is brought to you for free and open access by the School of Electrical and Electronic Engineering at ARROW@TU Dublin. It has been accepted for inclusion in Articles by an authorized administrator of ARROW@TU Dublin. For more information, please contact arrow.admin@tudublin.ie, aisling.coyne@tudublin.ie, gerard.connolly@tudublin.ie.

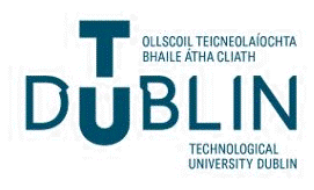




\section{Authors}

Z. N. Chen, Max Ammann, M.Y. W. Chia, and T.S. P. See

This article is available at ARROW@TU Dublin: https://arrow.tudublin.ie/engscheceart/26 


\title{
Circular annular planar monopoles with EM coupling
}

\author{
Z.N. Chen, M.J. Ammann, M.Y.W. Chia and T.S.P. See
}

\begin{abstract}
A circular annular planar monopole with electromagnetic coupling shows broadband properties. The planar radiator is electromagnetically coupled with a probe-fed strip, between which the medium is a thin dielectric sheet. The parametrical effects on the bandwidth are examined experimentally. The measurements have demonstrated that the proposed monopoles have the merit of broad impedance bandwidths in the order of $100 \%$ for VSWR $=2: 1$ and 4:1 for $\mathrm{VSWR}=3: 1$ and acceptable radiation patterns across the bandwidths.
\end{abstract}

\section{Introduction}

Monopoles have been widely used because of their simple structures yet powerful performances. To broaden the bandwidth of a monopole in its basic form, we can thicken or load the thin wire monopole. Another option is to replace the wires with planar elements to realise a noticeably broad bandwidth $[1,2]$. The up-to-date planar monopole designs include the various radiating elements, such as elliptical, rectangular, bow-tie-like and trapezoidal plates [27]. Of them, an elliptical disk achieved the 2:1 VSWR impedance bandwidth of nearly $1: 10$ at the price of larger lateral sizes. Recently, planar rectangular and triangular electromagnetically coupled monopoles have been presented experimentally and their impedance characteristics studied $[8,9]$. The enhanced impedance bandwidths reached up to $70 \%$ for $\mathrm{VSWR}=2: 1$ and $60 \%$ for $\mathrm{VSWR}=1.5: 1$.

This paper presents a new planar monopole with electromagnetically coupling (EMC) for broadband applications. The monopole comprises a circular annular planar radiator electromagnetically coupled with a probe-fed narrow strip, separated by a thin dielectric sheet. The achieved impedance bandwidths are of the order of $100 \%$ for $\operatorname{VSWR}=2: 1$ and $4: 1$ for $\mathrm{VSWR}=3: 1$. The radiation performances are acceptable within a quite broad bandwidth. The studies on the effects of the geometric parameters on the bandwidths provide helpful information for design considerations.

\section{Designs and measurements}

Fig. 1 shows the co-ordinates system and the sketch of the circular annual planar monopole illustrating the radii $R$ and $r$. It is etched on to a circular PCB sheet of radius $R=20 \mathrm{~mm}$, thickness $t=60 \mathrm{~mm}$ and dielectric constant $\varepsilon_{r}=3.38$. The circular PCB is placed upright above a square ground plane of dimensions $320 \times 320 \mathrm{~mm}$. A copper strip of width $w=4 \mathrm{~mm}$ and length $l$ is centrally etched on to the

\section{IEE, 2003}

IEE Proceedings online no. 20030476

doi:10.1049/ip-map:20030476

Paper first received 20th January and in revised form 17th June 2002. Online publishing date: 26 June 2003

Z.N. Chen, M.Y.W. Chia and T.S.P. See are with the Institute for Infocomm Research, 20 Science Park Road, \#02-34/37 TeleTech Park, Singapore Science Park II 17674, Singapore

M.J. Ammann is with the School of Electronic and Communications Engineering, Dublin Institute of Technology, Dublin 8, Ireland

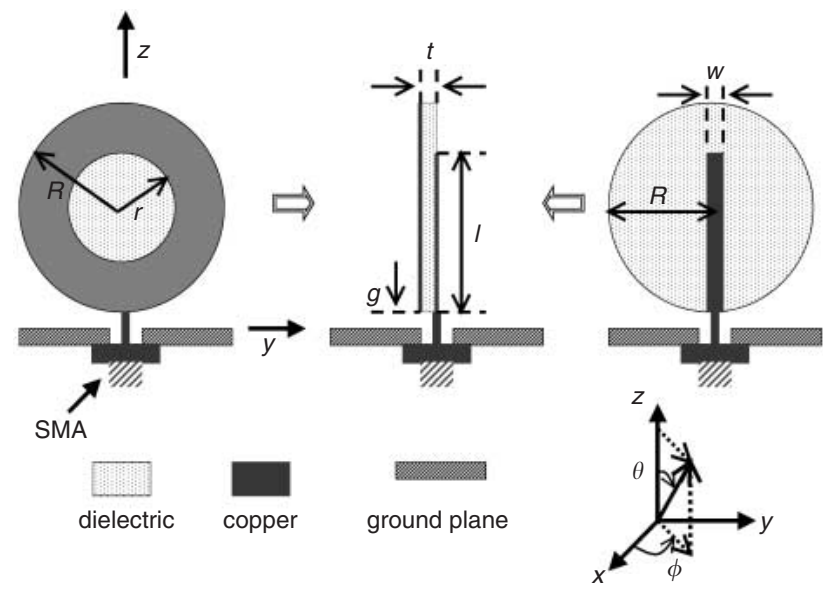

Fig. 1 Geometry of the proposed planar monopole

other side of the PCB sheet and vertically oriented. A coaxial probe of $0.6 \mathrm{~mm}$ radius, an extended inner conductor of a $50 \Omega$ SMA connector, feeds the strip at the midpoint of its bottom side. Thus, the planar monopole and the probe-fed strip are separated by the PCB sheet. The feedgap between the bottom side of the circular disk and the ground plane is $g$. Measurements on the VSWR and radiation patterns were carried out. The impedance bandwidth is calculated using the following formula:

$$
\mathrm{BW}= \begin{cases}2 \frac{\left(f_{u}-f_{l}\right)}{\left(f_{u}+f_{l}\right)} \times 100 \% & \mathrm{BW} \leq 100 \% \\ f_{u}: f_{l} & \mathrm{BW}>100 \%\end{cases}
$$

where $f_{u}$ and $f_{l}$ are the frequencies corresponding to the upper and lower edges of the bandwidth (FU/LEBW), respectively. In the measurements of the impedance, the monopoles with different radii $r$ and feedgaps $g$ are taken into account. The frequency range is $0.5-8.5 \mathrm{GHz}$ in the tests.

First, Fig. 2 shows the measured VSWR against frequency for the strip length $l$ ranging from $7.5-40 \mathrm{~mm}$, where the monopoles have radii $r=0 \mathrm{~mm}$ and feedgaps $g=1.6 \mathrm{~mm}$. It is seen that 2:1 VSWR well-matched bandwidths of $16.5-99.1 \%$ have been achieved when the length $l$ is reduced from $32.5 \mathrm{~mm}$ to $12.5 \mathrm{~mm}$. The $3: 1$ VSWR bandwidth is larger than $4.5: 1$ for $l=7.5 \mathrm{~mm}$. However, the FLEBW increases from $1.50 \mathrm{GHz}$ up to $1.72 \mathrm{GHz}$ as the length $l$ is reduced from $32.5 \mathrm{~mm}$ to $12.5 \mathrm{~mm}$. Table 1 provides the measured results for the other feedgaps $g=0.7 \mathrm{~mm}$ and $2.3 \mathrm{~mm}$. The conclusions are 

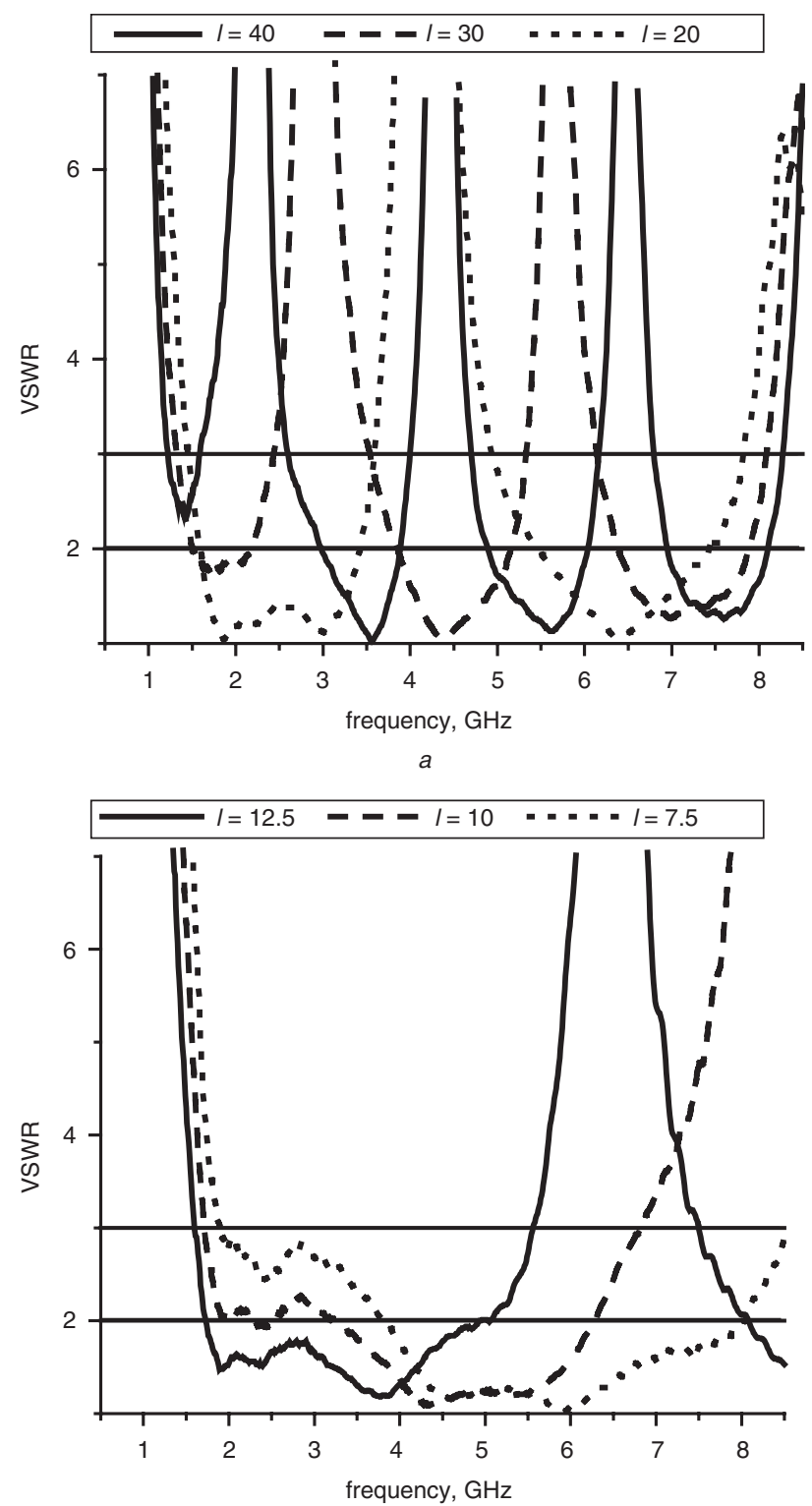

$b$

Fig. 2 Measured VSWR against the frequency for the different strip lengths $l$ for the feedgap $g=1.6 \mathrm{~mm}$ and radius $r=0 \mathrm{~mm}$

similar to the monopoles with $g=1.6 \mathrm{~mm}$ can be made, although the achieved bandwidths and the FLEBW for different feedgaps is slightly different.

The impedance features of the annular planar monopoles with concentric apertures of different radii $r=5,10$ and $15 \mathrm{~mm}$ were then studied experimentally. Tables $2-4$ provide the measured impedance bandwidths for $\mathrm{VSWR}=2: 1$ and $3: 1$, and the FLEBW. The feedgap $g$ is $0.7,1.6$ and $2.3 \mathrm{~mm}$. The strip length $l$ varies from 10 $40 \mathrm{~mm}$ in all cases. Fig. 3 further shows the comparisons of the measured FLEBW and bandwidths against the strip length $l$ with fixed feedgap $g=1.6 \mathrm{~mm}$ and the different radii $r$ and lengths $l$. Three important points can be observed from the Figures. Firstly, for a monopole, the longer the strip length, the lower the FLEBW. Secondly, the monopoles with radii $r=0$ and $5 \mathrm{~mm}$ have almost the same FLEBW, which are much lower than those in other cases with larger radii $r=10$ and $15 \mathrm{~mm}$. Thirdly, the monopoles with radii $r=0,5$ and $10 \mathrm{~mm}$ have nearly the same bandwidths, which become narrow as strip length $l$ increases. The maximum achieved bandwidths are around $100 \%$ for the radii $r=0$ and $5 \mathrm{~mm}$. Fig. 4 illustrates the

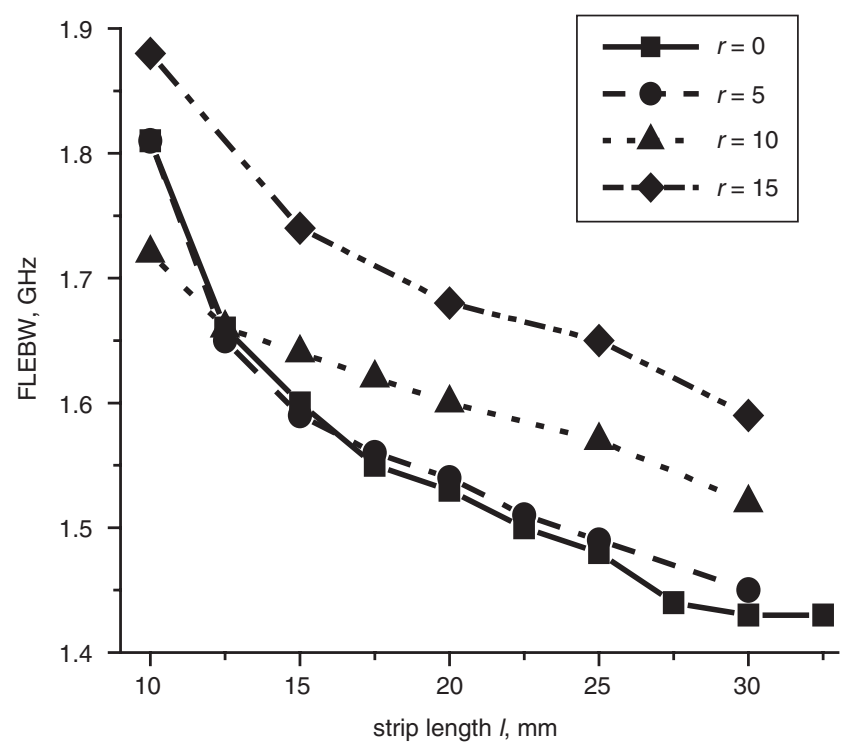

a

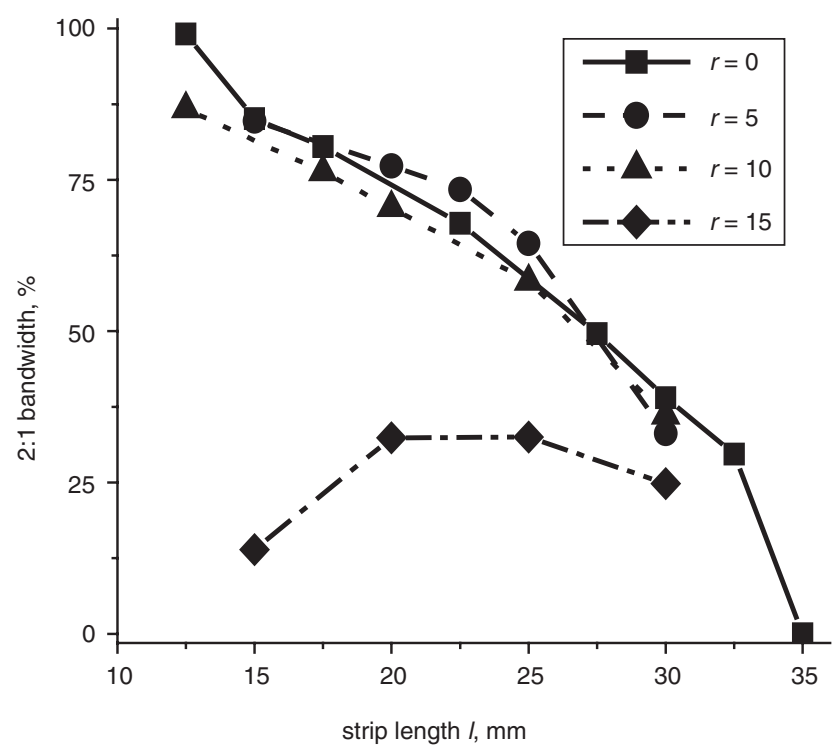

$b$

Fig. 3 Comparisons of achieved results

$a$ FLEBW against the strip lengths $l$ for the feedgap $g=1.6 \mathrm{~mm}$ and the different radii $r$

$b$ Bandwidths against the strip lengths $l$ for the feedgap $g=1.6 \mathrm{~mm}$ and the different radii $r$

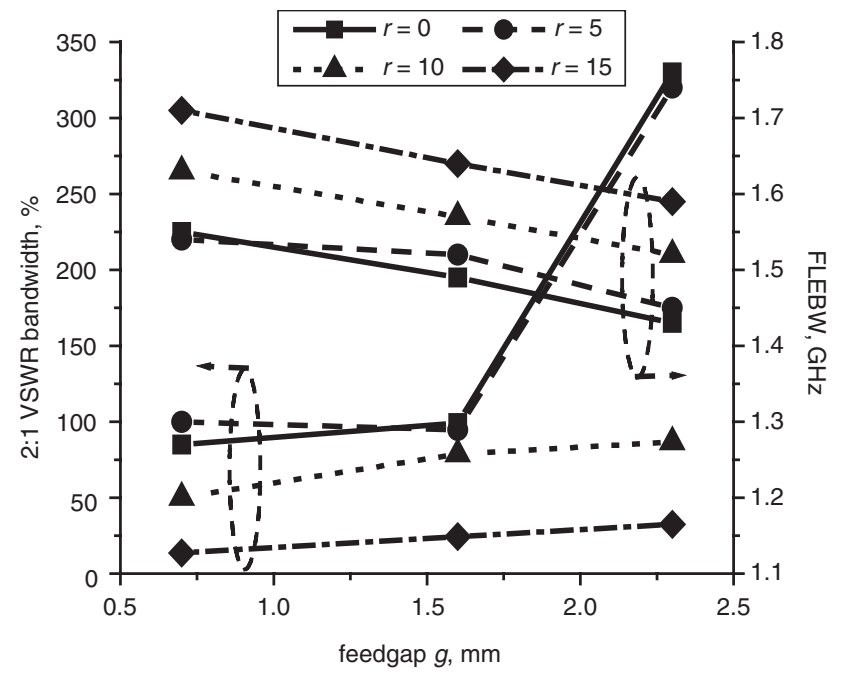

Fig. 4 Maximum attainable bandwidths and minimum FLEBW against the feedgap $g$ for the different radii $r$

IEE Proc.-Microw. Antennas Propag., Vol. 150, No. 4, August 2003 
Table 1: Measured impedance bandwidth (BW) and frequency corresponding to the lower edge of the bandwidth (FLEBW) for $r=0.0 \mathrm{~mm}$

\begin{tabular}{|c|c|c|c|c|c|c|c|c|c|c|c|c|}
\hline \multirow[t]{3}{*}{$I(\mathrm{~mm})$} & \multicolumn{4}{|c|}{$g=0.7 \mathrm{~mm}$} & \multicolumn{4}{|c|}{$g=1.6 \mathrm{~mm}$} & \multicolumn{4}{|c|}{$g=2.3 \mathrm{~mm}$} \\
\hline & \multicolumn{2}{|c|}{ VSWR $=2: 1$} & \multicolumn{2}{|c|}{ VSWR $=3: 1$} & \multicolumn{2}{|c|}{$V S W R=2: 1$} & \multicolumn{2}{|c|}{ VSWR $=3: 1$} & \multicolumn{2}{|c|}{ VSWR $=2: 1$} & \multicolumn{2}{|c|}{ VSWR = 3:1 } \\
\hline & $\begin{array}{l}\text { FLEBW } \\
(\mathrm{GHz})\end{array}$ & BW & $\begin{array}{l}\text { FLEBW } \\
(\mathrm{GHz})\end{array}$ & BW & $\begin{array}{l}\text { FLEBW } \\
(\mathrm{GHz})\end{array}$ & BW & $\begin{array}{l}\text { FLEBW } \\
(\mathrm{GHz})\end{array}$ & BW & $\begin{array}{l}\text { FLEBW } \\
(\mathrm{GHz})\end{array}$ & BW & $\begin{array}{l}\text { FLEBW } \\
(\mathrm{GHz})\end{array}$ & BW \\
\hline 40.0 & 3.12 & $0 \%$ & 1.28 & $25.3 \%$ & 2.96 & $0 \%$ & 1.22 & $25.7 \%$ & 2.82 & $0 \%$ & 1.17 & $28.6 \%$ \\
\hline 35.0 & 3.54 & $0 \%$ & 1.32 & $44.7 \%$ & 3.34 & $0 \%$ & 1.25 & $46.6 \%$ & 3.18 & $0 \%$ & 1.21 & $42.3 \%$ \\
\hline 32.5 & 1.55 & $29.7 \%$ & 1.36 & $49.7 \%$ & 1.50 & $16.5 \%$ & 1.30 & $52.3 \%$ & 1.43 & $10.6 \%$ & 1.23 & $54.9 \%$ \\
\hline 30.0 & 1.55 & $39.0 \%$ & 1.38 & $57.7 \%$ & 1.49 & $38.5 \%$ & 1.33 & $58.5 \%$ & 1.43 & $22.4 \%$ & 1.27 & $58.9 \%$ \\
\hline 27.5 & 1.56 & $49.6 \%$ & 1.40 & $64.4 \%$ & 1.51 & $44.7 \%$ & 1.36 & $65.7 \%$ & 1.44 & $42.6 \%$ & 1.30 & $67.3 \%$ \\
\hline 25.0 & 1.57 & $58.2 \%$ & 1.42 & $70.3 \%$ & 1.53 & $59.0 \%$ & 1.39 & $71.9 \%$ & 1.48 & $49.7 \%$ & 1.32 & $75.5 \%$ \\
\hline 22.5 & 1.60 & $65.3 \%$ & 1.48 & $75.1 \%$ & 1.55 & $67.0 \%$ & 1.41 & $78.7 \%$ & 1.50 & $67.8 \%$ & 1.35 & $81.6 \%$ \\
\hline 20.0 & 1.63 & $71.1 \%$ & 1.51 & $81.3 \%$ & 1.59 & $73.3 \%$ & 1.45 & $84.9 \%$ & 1.53 & $74.6 \%$ & 1.39 & $87.2 \%$ \\
\hline 17.5 & 1.67 & $77.7 \%$ & 1.56 & $87.3 \%$ & 1.62 & $79.1 \%$ & 1.49 & $90.0 \%$ & 1.55 & $80.5 \%$ & 1.43 & $91.9 \%$ \\
\hline 15.0 & 1.73 & $85.0 \%$ & 1.62 & $98.3 \%$ & 1.66 & $85.1 \%$ & 1.55 & $98.2 \%$ & 1.60 & $84.7 \%$ & 1.49 & $96.7 \%$ \\
\hline 12.5 & 1.84 & $33.5 \%$ & 1.67 & $3.4: 1$ & 1.72 & $99.1 \%$ & 1.60 & $3.5: 1$ & 1.66 & $87.8 \%$ & 1.55 & $3.5: 1$ \\
\hline 10.0 & 3.86 & $0 \%$ & 1.81 & 3.9:1 & 2.23 & $0 \%$ & 1.71 & $4: 1$ & 1.81 & 3.3:1 & 1.66 & 3.9:1 \\
\hline 7.5 & 4.21 & $0 \%$ & 2.36 & $0 \%$ & 3.76 & $0 \%$ & 1.90 & $>4.5: 1$ & 3.17 & $0 \%$ & 1.76 & $4.7: 1$ \\
\hline 5.0 & 6.11 & $0 \%$ & 4.12 & $0 \%$ & 4.17 & $0 \%$ & 3.71 & $0 \%$ & 3.76 & $0 \%$ & 2.34 & $0 \%$ \\
\hline
\end{tabular}

Table 2: Measured impedance bandwidth (BW) and frequency corresponding to the lower edge of the bandwidth (FLEBW) for $r=5.0 \mathrm{~mm}$

\begin{tabular}{|c|c|c|c|c|c|c|c|c|c|c|c|c|}
\hline \multirow[t]{3}{*}{$I(\mathrm{~mm})$} & \multicolumn{4}{|c|}{$g=0.7 \mathrm{~mm}$} & \multicolumn{4}{|c|}{$g=1.6 \mathrm{~mm}$} & \multicolumn{4}{|c|}{$g=2.3 \mathrm{~mm}$} \\
\hline & \multicolumn{2}{|c|}{ VSWR $=2: 1$} & \multicolumn{2}{|c|}{ VSWR $=3: 1$} & \multicolumn{2}{|c|}{$V S W R=2: 1$} & \multicolumn{2}{|c|}{$V S W R=3: 1$} & \multicolumn{2}{|c|}{ VSWR $=2: 1$} & \multicolumn{2}{|c|}{ VSWR = 3:1 } \\
\hline & $\begin{array}{l}\text { FLEBW } \\
\text { (GHz) }\end{array}$ & BW & $\begin{array}{l}\text { FLEBW } \\
(\mathrm{GHz})\end{array}$ & BW & $\begin{array}{l}\text { FLEBW } \\
(\mathrm{GHz})\end{array}$ & BW & $\begin{array}{l}\text { FLEBW } \\
\text { (GHz) }\end{array}$ & BW & $\begin{array}{l}\text { FLEBW } \\
(\mathrm{GHz})\end{array}$ & BW & $\begin{array}{l}\text { FLEBW } \\
(\mathrm{GHz})\end{array}$ & BW \\
\hline 40.0 & 2.85 & $0 \%$ & 1.24 & $12.1 \%$ & 2.33 & $0 \%$ & 1.20 & $15.4 \%$ & 2.27 & $0 \%$ & 1.18 & $17.1 \%$ \\
\hline 30.0 & 1.54 & $33.5 \%$ & 1.39 & $46.8 \%$ & 1.52 & $29.2 \%$ & 1.33 & $50.1 \%$ & 1.45 & $22.1 \%$ & 1.29 & $51.7 \%$ \\
\hline 25.0 & 1.60 & $60.0 \%$ & 1.47 & $69.6 \%$ & 1.56 & $61.9 \%$ & 1.42 & $72.6 \%$ & 1.49 & $64.5 \%$ & 1.37 & $75.2 \%$ \\
\hline 22.5 & 1.62 & $69.9 \%$ & 1.49 & $79.6 \%$ & 1.58 & $72.3 \%$ & 1.44 & $82.4 \%$ & 1.51 & $73.4 \%$ & 1.39 & $84.4 \%$ \\
\hline 20.0 & 1.64 & $75.3 \%$ & 1.51 & $86.0 \%$ & 1.60 & $76.9 \%$ & 1.47 & $87.4 \%$ & 1.54 & $77.3 \%$ & 1.41 & $89.0 \%$ \\
\hline 17.5 & 1.65 & $79.1 \%$ & 1.53 & $89.5 \%$ & 1.61 & $80.1 \%$ & 1.47 & $91.9 \%$ & 1.56 & $79.8 \%$ & 1.43 & $91.5 \%$ \\
\hline 15.0 & 1.67 & $83.0 \%$ & 1.56 & $95.5 \%$ & 1.62 & $84.7 \%$ & 1.50 & $95.3 \%$ & 1.59 & $83.3 \%$ & 1.46 & $96.8 \%$ \\
\hline 12.5 & 1.75 & $99.9 \%$ & 1.63 & $3.4: 1$ & 1.71 & $94.7 \%$ & 1.59 & $3.5: 1$ & 1.65 & $87.9 \%$ & 1.54 & $3.5: 1$ \\
\hline 10.0 & 3.81 & $0 \%$ & 1.77 & $4: 1$ & 1.88 & $30.2 \%$ & 1.69 & $3.9: 1$ & 1.81 & 3.2:1 & 1.65 & $3.9: 1$ \\
\hline
\end{tabular}

Table 3: Measured impedance bandwidth (BW) and frequency corresponding to the lower edge of the bandwidth (FLEBW) for $r=10.0 \mathrm{~mm}$

\begin{tabular}{|c|c|c|c|c|c|c|c|c|c|c|c|c|}
\hline \multirow[t]{3}{*}{$I(\mathrm{~mm})$} & \multicolumn{4}{|c|}{$g=0.7 \mathrm{~mm}$} & \multicolumn{4}{|c|}{$g=1.6 \mathrm{~mm}$} & \multicolumn{4}{|c|}{$g=2.3 \mathrm{~mm}$} \\
\hline & \multicolumn{2}{|c|}{ VSWR $=2: 1$} & \multicolumn{2}{|c|}{ VSWR = 3:1 } & \multicolumn{2}{|c|}{ VSWR $=2: 1$} & \multicolumn{2}{|c|}{ VSWR = 3:1 } & \multicolumn{2}{|c|}{ VSWR $=2: 1$} & \multicolumn{2}{|c|}{ VSWR $=3: 1$} \\
\hline & $\begin{array}{l}\text { FLEBW } \\
(\mathrm{GHz})\end{array}$ & BW & $\begin{array}{l}\text { FLEBW } \\
\text { (GHz) }\end{array}$ & BW & $\begin{array}{l}\text { FLEBW } \\
(\mathrm{GHz})\end{array}$ & BW & $\begin{array}{l}\text { FLEBW } \\
(\mathrm{GHz})\end{array}$ & BW & $\begin{array}{l}\text { FLEBW } \\
(\mathrm{GHz})\end{array}$ & BW & $\begin{array}{l}\text { FLEBW } \\
(\mathrm{GHz})\end{array}$ & BW \\
\hline 40.0 & 2.25 & $0 \%$ & 1.82 & $0 \%$ & 1.88 & $0 \%$ & 1.78 & $0 \%$ & 1.85 & $0 \%$ & 1.75 & $0 \%$ \\
\hline 30.0 & 1.63 & $29.3 \%$ & 1.49 & $39.8 \%$ & 1.57 & $33.4 \%$ & 1.43 & $44.1 \%$ & 1.52 & $36.1 \%$ & 1.39 & $46.8 \%$ \\
\hline 25.0 & 1.67 & $50.2 \%$ & 1.55 & $59.7 \%$ & 1.61 & $55.3 \%$ & 1.49 & $63.9 \%$ & 1.57 & $58.2 \%$ & 1.45 & $66.7 \%$ \\
\hline 20.0 & 1.69 & $48.1 \%$ & 1.59 & $72.0 \%$ & 1.64 & $67.2 \%$ & 1.53 & $76.9 \%$ & 1.60 & $70.4 \%$ & 1.48 & $79.7 \%$ \\
\hline 17.5 & 1.74 & $38.9 \%$ & 1.62 & $77.7 \%$ & 1.66 & $74.0 \%$ & 1.55 & $84.1 \%$ & 1.62 & $76.3 \%$ & 1.51 & $85.8 \%$ \\
\hline 15.0 & 1.79 & $34.3 \%$ & 1.64 & $3.4: 1$ & 1.68 & $78.7 \%$ & 1.58 & $91.4 \%$ & 1.64 & $80.5 \%$ & 1.52 & $91.4 \%$ \\
\hline 12.5 & 1.80 & $30.2 \%$ & 1.65 & $3.6: 1$ & 1.72 & $39.6 \%$ & 1.61 & $3.6: 1$ & 1.66 & $86.7 \%$ & 1.57 & $3.6: 1$ \\
\hline 10.0 & 4.01 & $0 \%$ & 1.71 & $4: 1$ & 1.80 & $33.7 \%$ & 1.65 & $4: 1$ & 1.72 & $39.3 \%$ & 1.62 & $4: 1$ \\
\hline
\end{tabular}


Table 4: Measured impedance bandwidth (BW) and frequency corresponding to the lower edge of the bandwidth (FLEBW) for $r=15.0 \mathrm{~mm}$

\begin{tabular}{|c|c|c|c|c|c|c|c|c|c|c|c|c|}
\hline \multirow[t]{3}{*}{$I(\mathrm{~mm})$} & \multicolumn{4}{|c|}{$g=0.7 \mathrm{~mm}$} & \multicolumn{4}{|c|}{$g=1.6 \mathrm{~mm}$} & \multicolumn{4}{|c|}{$g=2.3 \mathrm{~mm}$} \\
\hline & \multicolumn{2}{|c|}{ VSWR $=2: 1$} & \multicolumn{2}{|c|}{ VSWR $=3: 1$} & \multicolumn{2}{|c|}{ VSWR $=2: 1$} & \multicolumn{2}{|c|}{ VSWR $=3: 1$} & \multicolumn{2}{|c|}{ VSWR $=2: 1$} & \multicolumn{2}{|c|}{ VSWR $=3: 1$} \\
\hline & $\begin{array}{l}\text { FLEBW } \\
(\mathrm{GHz})\end{array}$ & BW (\%) & $\begin{array}{l}\text { FLEBW } \\
(\mathrm{GHz})\end{array}$ & BW (\%) & $\begin{array}{l}\text { FLEBW } \\
(\mathrm{GHz})\end{array}$ & BW (\%) & $\begin{array}{l}\text { FLEBW } \\
(\mathrm{GHz})\end{array}$ & BW (\%) & $\begin{array}{l}\text { FLEBW } \\
(\mathrm{GHz})\end{array}$ & BW (\%) & $\begin{array}{l}\text { FLEBW } \\
(\mathrm{GHz})\end{array}$ & $\mathrm{BW}(\%)$ \\
\hline 40.0 & 4.34 & 0.0 & 1.76 & 0.0 & 3.66 & 0.0 & 1.72 & 0.0 & 1.83 & 0.0 & 1.71 & 0.0 \\
\hline 30.0 & 1.71 & 13.6 & 1.60 & 23.7 & 1.64 & 21.3 & 1.51 & 30.8 & 1.59 & 24.8 & 1.46 & 34.6 \\
\hline 25.0 & 1.81 & 7.5 & 1.63 & 30.2 & 1.69 & 24.4 & 1.59 & 37.3 & 1.65 & 32.5 & 1.53 & 42.3 \\
\hline 20.0 & 5.82 & 0.0 & 1.69 & 25.8 & 1.73 & 16.9 & 1.62 & 42.0 & 1.68 & 32.4 & 1.58 & 47.0 \\
\hline 15.0 & 4.08 & 0.0 & 1.72 & 23.1 & 6.24 & 0.0 & 1.66 & 36.9 & 1.74 & 13.9 & 1.62 & 44.2 \\
\hline 10.0 & 3.99 & 0.0 & 1.81 & 10.0 & 3.96 & 0.0 & 1.71 & 31.9 & 1.88 & 2.6 & 1.68 & 35.7 \\
\hline
\end{tabular}
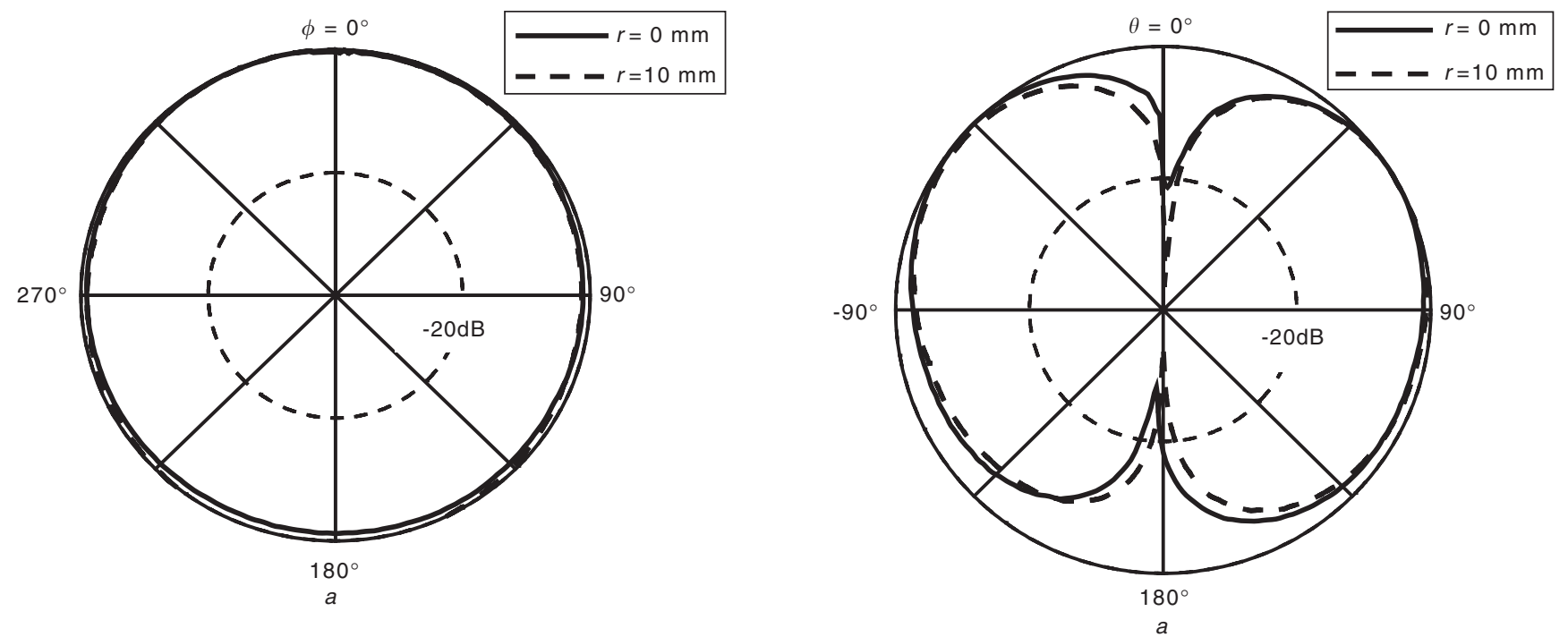

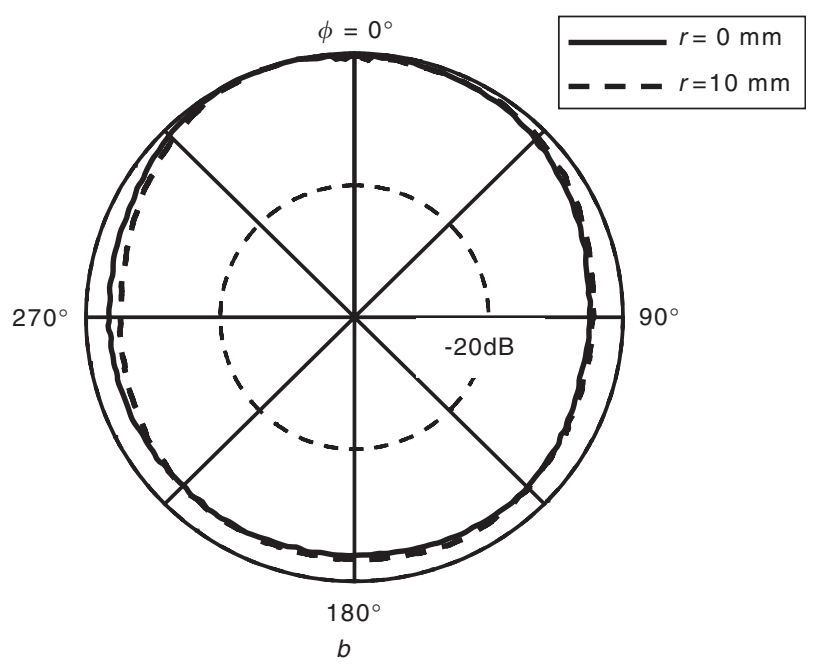

Fig. 5 Measured radiation patterns for the radii $r=0$ and $10 \mathrm{~mm}$ in the $x-y$ plane

$a$ At $1.8 \mathrm{GHz}$

$b$ At $3.8 \mathrm{GHz}$

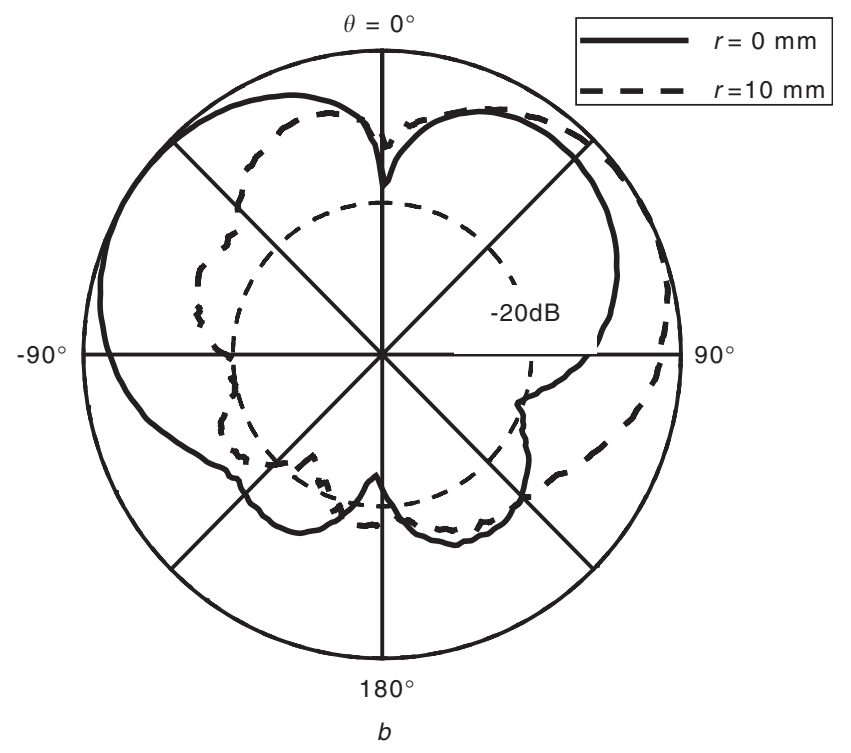

Fig. 6 Measured radiation patterns for the radii $r=0$ and $10 \mathrm{~mm}$ in the $x-z$ plane $a$ At $1.8 \mathrm{GHz}$

$b$ At $3.8 \mathrm{GHz}$ 

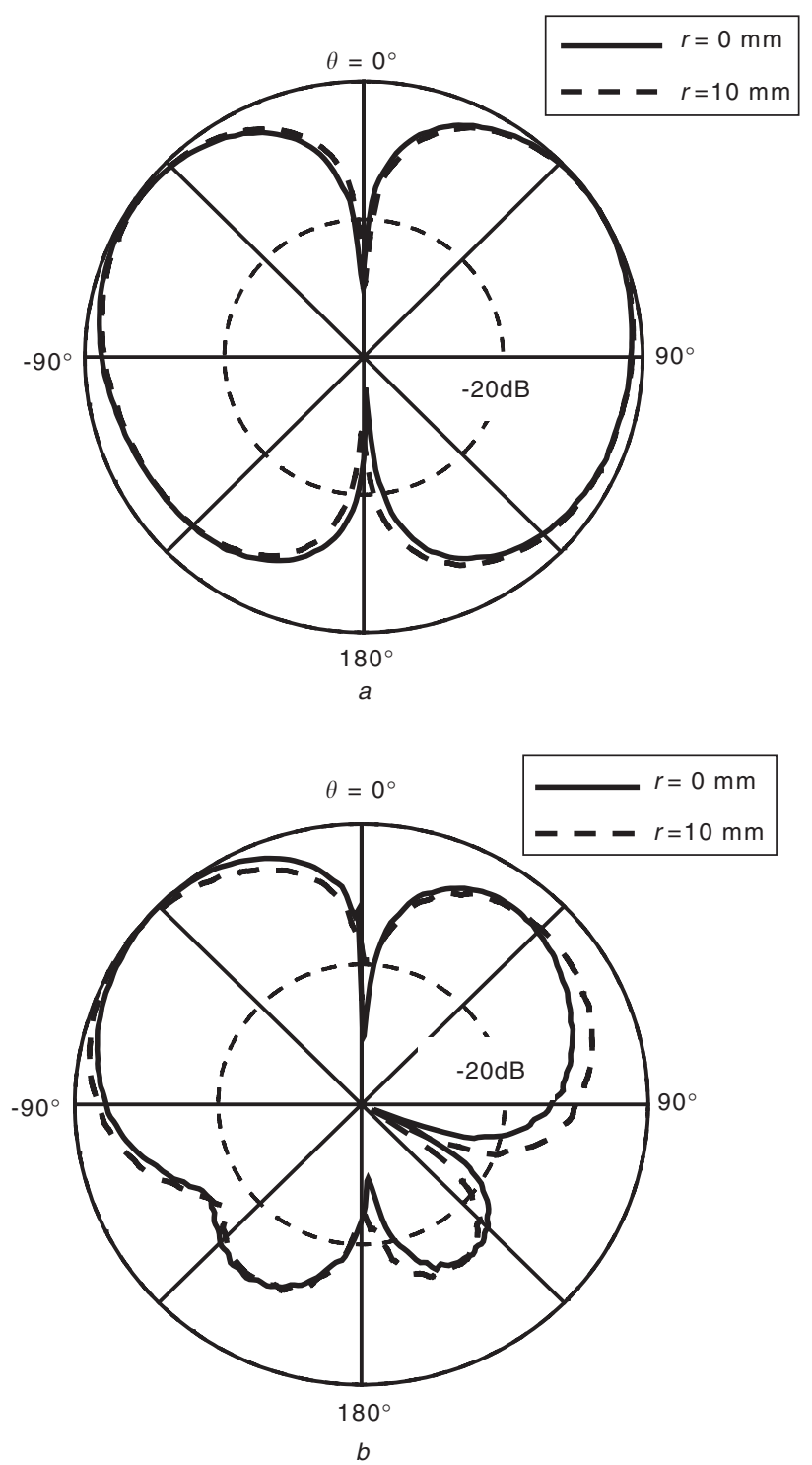

Fig. 7 Measured radiation patterns for the radii $r=0$ and $10 \mathrm{~mm}$ in the $y-z$ plane

$a$ At $1.8 \mathrm{GHz}$

$b$ At $3.8 \mathrm{GHz}$

maximum attainable 2:1 VSWR bandwidths and minimum obtainable FLEBW for the different feedgaps $g$. It is seen that the larger the feedgap $g$, the lower the FLEBW. This is because the overall height of the monopole is increased. The larger the feedgap $g$, the wider the bandwidth, especially for the monopoles with apertures of radii $r=0$ and $5 \mathrm{~mm}$.
Finally, the radiation patterns were measured in three principle planes at 1.8 and $3.8 \mathrm{GHz}$ for the apertures of radii $r=0$ and $10 \mathrm{~mm}$. Fig. 5 illustrates the patterns for the $\phi$ cut ( $x-y$ plane) and shows the near omnidirectional patterns at both frequencies, with the aperture having little effect on the patterns. Figs. 6 and 7 illustrate the patterns for the $\theta=0^{\circ}$ and $\theta=90^{\circ}$ cuts $(x-z$ and $y-z$ planes, respectively), which are typically monopole-like. The maximum gain at $1.8 \mathrm{GHz}$ was found to be $2.8 \mathrm{dBi}$ for $\phi=0^{\circ}$ at $\theta=25-45^{\circ}$. The maximum gain in the ground plane $\left(\theta=90^{\circ}\right)$ was $0.8 \mathrm{dBi}$.

\section{Conclusions}

A circular annular planar monopole electromagnetically coupled with a probe-fed strip has been proposed to improve the impedance performance of the existing rectangular or triangular planar EMC monopoles. The measurements on the proposed monopoles have demonstrated that this design has a noticeably broad impedance bandwidth of the order of $100 \%$ for VSWR $=2: 1$ and $4: 1$ for $\operatorname{VSWR}=3: 1$ with acceptable monopole-like radiation patterns. Moreover, the parametric studies have shown that both the length of the probe-fed strip and the feedgap have significant effects on the impedance bandwidth. The annular monopole is appropriate for low-frequency applications due to its reduced volume and weight.

\section{References}

1 Brown, G.H., and Woodward, O.M. Jr.: 'Experimentally determined radiation characteristics of conical and triangular antennas', RCA Rev., 1952, 13, (4), pp. 425-452

2 Honda, S., Ito, M., Seki, H., and Jinbo, Y.: 'A disk monopole antenna with 1:8 impedance bandwidth and omnidirectional radiation pattern'. ISAP'92, Sapporo, 1992, Japan pp. 1145-1148

3 Agrawall, N.P., Kumar, G., and Ray, K.P.: 'Wide-band planar monopole antenna', IEEE Trans. Antennas Propag., 1998, 46, (2), pp. 294-295

4 Ammann, M.J.: 'Square planar monopole antenna'. National Conf. Antennas Propagat, York, England, 1999, pp. 37-40

5 Chen, Z.N.: 'Impedance characteristics of planar bow-tie-like monopole antennas', Electron. Lett., 2000, 36, (13), pp. 1100-1101

6 Ammann, M.J.: 'The pentagonal planar monopole for digital mobile terminals; bandwidth considerations and modelling'. Int. Conf. on Antennas and propagation, 2001, Vol. 1, pp. 82-85

7 Chen, Z.N., and Chia, M.Y.W.: 'Impedance characteristics of trapezoidal planar monopole antenna', Microw. Opt. Technol. Lett., 2000, 27, (2), pp. 120-122

8 Chen, Z.N.: 'Broadband planar monopole antenna', IEE Proc. Microw. Antennas Propag., 2000, 147, (6), pp. 526-528

9 Chen, Z.N., and Chia, M.Y.W: 'Impedance characteristics of EMC triangular planar monopoles', Electron. Lett., 2001, 37, (21), pp. 12711272 